\title{
AEPRD: An Enhanced Algorithm for Predicting Results of Orthodontic Operations
}

\author{
Ammar Thaher Yaseen Al Abd Alazeez
}

Computer Science Department, Computer Science and Mathmatics College, University of Mosul, Mosul, Iraq

E-mail: ammarthaher@uomosul.edu.iq

(Received July 25, 2020; Accepted October 07, 2020; Available online March 01, 2021)

DOI: 10.33899/edusj.2020.127785.1094, (c) 2020, College of Education for Pure Science, University of Mosul.

This is an open access article under the CC BY 4.0 license (http://creativecommons.org/licenses/by/4.0/).

\begin{abstract}
The face is the most critical component which is clear on first sight for an individual. Soft tissue of the face alongside the fundamental dentoskeletal tissues portrays the facial attributes of a person. Social affirmation, mental well-being, and self-esteem of an individual are related to physical appearance. The impression of a charming face is generally passionate with ethnicity, age, sexual orientation, culture, and character influencing ordinary facial attributes. Strikingly, facial properties are regularly packed in profile. Orthodontic assurance and treatment orchestrating are continuously being established on profiles rather than basically on Angle's concept of molar relationship. It was seen that particular skeletal exact guidelines, proportion of constitution of the soft tissue, and facial solid position can affect the assessment of the profile. One of the uncommon challenges in orthodontics is the treatment orchestrating and the leading body of orthognathic careful cases. These cases require a mix of both orthodontics and orthognathic medical procedure to accomplish an even impediment, appropriate function, and agreeable facial feel. It is obvious in the literature that there are three main types of malocclusions: Class I which includes people who have a normal bite, Class II which includes people who have an overbite, and Class III which includes people who have an underbite. Early analysis of malocclusion is exceptionally helpful to get legitimate straight teeth. Thus, in this paper we built up a straightforward PC supported system using image processing techniques that could help foreseeing teeth impediment. In other words, we take an image of an individual and order it into one of the three primary types: Class I, Class II, and Class III and predict the post-treatments of Class II and Class III. This study gives information which can be used in treatment orchestrating by authorities, for instance, orthodontists, prosthodontists, plastic specialists, and maxillofacial experts, who have the ability to change the soft tissue facial characteristics.
\end{abstract}

Keywords: Image Segmentation Algorithms, Image Prediction Algorithms, Image analysis, Malaclusion, Straight Teeth

$$
\begin{aligned}
& \text { : خوارزمية محسنة لتوقع نتائج عمليات تقويم الاسنان AEPRD } \\
& \text { د. عمار ظاهر ياسين ال عبد العزيز } \\
& \text { قسم علوم الحاسوب, كلية علوم الحاسوب والرياضيات, جامعة الموصل, الموصل, العراق }
\end{aligned}
$$


مما لا شك فيه ان وجه الانسان هو الجزء الاهم من الجسم لانه يحتوي على المظهر الخارجي للفرد. وان تحليل الانسجة الخارجية

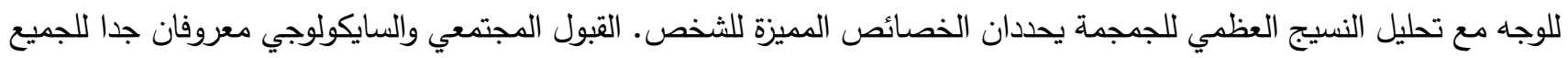
وهما متعلقان بالخصائص الفيزيائية لاي شخص. مفهوم تقبل الوجه هو خاص جدا لانه متعلق بعدة امور دقيقة منها العرق، العمر ،

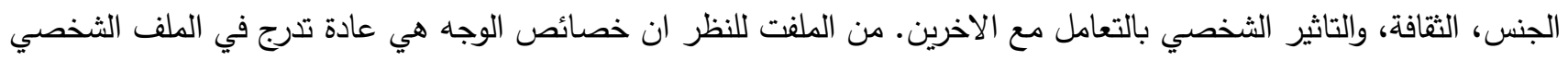

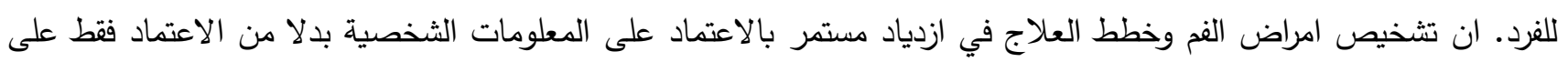

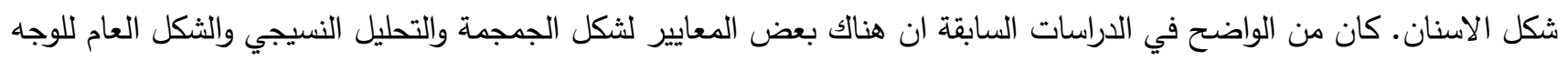
والتي من الممكن ان تؤثر على المعلومات الثخصية للفرد. ان من المشكلات والتحديات الصعبة في علم الاسنان هو الخطط العلاجية وادارة الحالات المرضية الخاصة والتي تتطلب تدخلات جراحية. هذه الحالات تتطلب الربط بين علم تقويم الاسنان والتدخلات الجراحية لانجاز التوازن المنشود في عملية اطباق الاسنان والحصول على وظائف فمية مميزة كالنطق الواضح وكذلك الحصول على التجميل

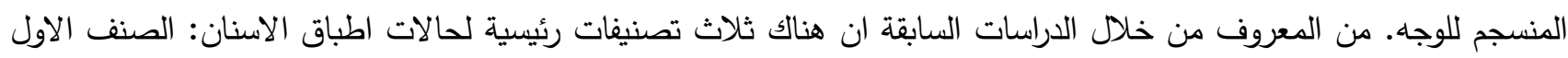
I Class II والذي يثمل الاثخاص الذين لديهم حالة بروز

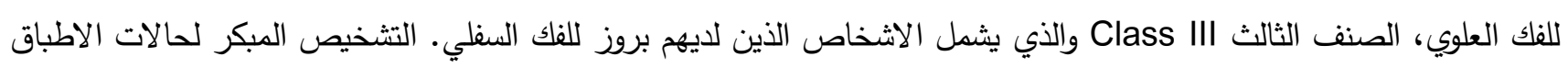
الفي غير الصحيح مهم جدا للحصول على اطباق اسنان ميميز بعد التصحيح. لذلك في هذا البحث قمنا بتطوير نظام حاسوبي بسيط يعتمد على تقنيات معالجة الصور للمساعدة في تصنيف حالات اطباق الاسنان ومن ثم توقع نتائج الحالات العلاجية بعد اجراء

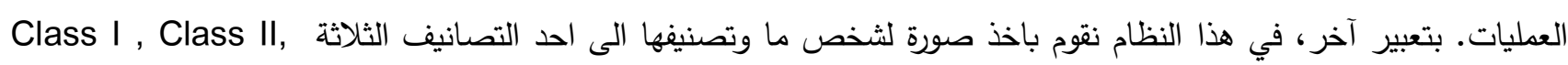

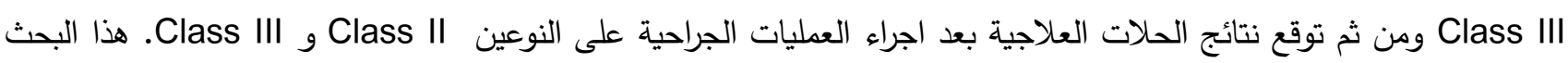

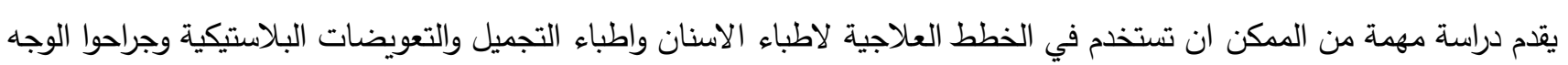

$$
\text { والفكين والذين يملكون القابلية على تحسين خصائص المظهر الخارجي للوجه. }
$$

الكلمات المفتاحية: خوارزميات تقطيع الصور، خوارزميات التوقع للصور، تحليل الصور، حالات اطباق الاسنان غير الصحيحة،

تقويم الاسنان

\section{Introduction}

Orthodontics is a part of dentistry that treats malocclusion, a condition where the teeth are not effectively situated when the mouth is shut. This outcome in an inappropriate chomp. An orthodontist works in making the teeth straight. Treatment can be restorative; to improve an individual's appearance, however it frequently means to improve oral function too [1]. The accomplishment of an orthodontic treatment is every now and again identified with the improvement gotten in the patient's facial appearance, which fuses the soft tissue profile. The face is considered as the most alterable piece of the body, factors depend on shape, size, features, or a mix of these. In addition, since there is broad assortment in the soft tissue covering the face, misleading closures can be conveyed if assurance and treatment orchestrating rely upon dental and skeletal estimations alone [2].

The utilization of computer assisted diagnosis (CAD) of illness is settled in clinical radiology, having been used since the 1980's at the University of Chicago and other clinical communities for help with the determination of lung knobs, bosom disease, osteoporosis and other complex radiographic undertakings. A significant qualification has been made in the clinical network between automated computer diagnosis versus computer-aided diagnosis. The fundamental difference is that in automated computer diagnosis, the computer does the assessment of the analytic material, i.e., radiographs, and arrives at the last determination with no human information. In computer-aided diagnosis; both a 
clinical practitioner and a PC assess the radiograph and arrive at a finding independently. Contingent upon the expert's certainty level, the person will at that point either make the last determination or utilize the PC's conclusion, in the event that it is not quite the same as the specialist's [3].

Orthodontics, style, and visual aids for soft tissue expectation have progressed since the mid-1970s from the use of acidic corrosive induction following paper to PC based line drawings to progressively introduce day advancements during the 1990s where PCs could alter open minded photographs attempting to anticipate careful results. Visual treatment objective (VTO) pictures help the orthodontist to anticipate hard and soft tissue changes that may happen in light of clinical strategy and can be utilized to arrive at a treatment plan for orthognathic cases and to talk with patients and experts. $70 \%$ of fast approaching orthognathic clinical strategy patients notice style as their standard motivation, further including the essentialness of soft tissue treatment orchestrating. It is the expert's genuine and good commitment to light up the patient with respect to the perils versus benefits, decisions of spread versus clinical method, and treatment versus no treatment. Notwithstanding, VTOs may prompt ridiculous patient desires causing disappointment with postsurgical results. This is a substantial worry, as the mistakes of the forecast in two-jaw careful cases are not surely known [4].

Early dissection of malocclusion is significant to get legitimate straight teeth and help in a sharp decrease in the dental ailment rate. Because of the creating receptiveness to clinical imaging, the clinical applications have better impact on industrious thought [4] [5]. Thusly, in this paper we built up a basic PC supported system that can help in predicting teeth impediment operations. In other words, we take a photo of an individual and characterize it into one of the three primary types Class I, Class II, and Class III and predict the post-operations of Class II and Class III to help for additional treatment. We propose a new strategy relying upon image processing and statistical techniques. This procedure depends on preprocessing images, isolating the dataset into two gatherings: dataset before operations and dataset after operations, and predicting the new pictures. The novelty here is to develop a simple image processing method combining with basic statistical techniques to predict dental image operations. This methodology was tried on gathered datasets and has exhibited a decent presentation of recognition.

\section{Related Work}

Soft tissue investigation assumes a significant role in orthodontics where it helps in the finding, treatment arranging, improve treatment achievement and build up ideal facial harmony. The soft tissues are a main consideration in deciding the outside facial appearance. Peterman et al. [4] introduced Dolphin Imaging programming apparatus that can be utilized for case acquaintance and patient guidance and with get patient's informed consent for two-jaw orthognathic cautious treatment plans. The VTO programming framework could be useful for net turns of events and forecasts of twojaw careful results during treatment organizing anyway is conflicting for treatment masterminding definite advancements when estimation run is $<5 \mathrm{~mm}$. Also, the lower lip desire is the least accurate in this program for two-jaw careful cases. The user of this program must be aware of thwart absurd patient wants and frustration [5].

Ben Ali et al. [4] proposed a neural network based strategy (DenNN) for order X-ray pictures. In the structure of the paper, the administrator under focus has an occupation to mastermind biomedical pictures by AI with the objective of finding clinically significant pathology plans. These characterization activities depend on dynamic apparatus. Be that as it may, the entomb patient fluctuation presents numerous difficulties for the conventional characterization methods. These have generally been designed and parameterized on little datasets or on a quite certain partner. Plus, this methodology requests X-ray pictures which may not be accessible constantly.

Alfarra et al. [6] proposed a methodology named (DenSTM) for Malay patients utilizing soft tissue profile. The eleven parameters in Holdaway investigation were consequently determined utilizing Planmeca Romexis Cephalometric Analysis Software program once the anatomical focuses have been digitized for every sidelong cephalogram. In spite of the fact that this product is exceptionally helpful 
for tolerant picture investigation and predicts careful medicines, it works with explicit gathering of individuals (Malaysian) and takes long calculation time.

Muhammed et al. [7] introduced a technique for drawing the cephalometric radiograph pictures. The examination expected to consider the unfaltering nature of the two drawing procedures (anatomic point and deviation line system). The model contains 100 cephalometric radiographs of patients with conventional obstruction and recognized facial profile, ten exact estimations along the soft tissue structure were evaluated by the 2 drawing strategies by 3 orthodontist experts and inspected quantifiably to find means and standard deviation and to be taken a gander at by intra-class relationship coefficient. In spite of the fact that this technique could be utilized to distinguish the dental picture class, it relies upon the inspectors to check the conclusive outcomes which is not generally accessible. Jader et al. [8] proposed an approach for segmenting dental panoramic images. In this technique they presented a segmentation system based on mask region based convolutional neural network to accomplish an instance segmentation. The work proposed by Lee et al. [9] aimed at locating the bones to suppress them from other areas at a later stage. To determine the boundaries, they proposed to use Active Shape Model (ASM). Their solution was based on using Generalized Hough Transform (GHT) but with a local sampling scheme i.e. generating a different template for each processed image. A sequence of enhancements operations (bilateral filter and histogram equalization) and Sobel operator to detect the border of bones were applied before the tablemate was selected from the low-edge image. After that, GHT followed by a Gaussian for smoothing, Otsu for thresholding, and opening and closing operations was used to obtain boundary.

Li et al. [10] presented a method that segments from X-ray radiograph. Their proposal started by detection boundaries using ASM so all later operations were applied on segmented fields. After that, the median filter was used to smooth the image before it was subtracted from the original one to obtain a detail image. At this point, a small threshold was applied for segmentation. The resulting binary image was then smoothed using a small sliding window that either set their pixel's value to 0 or 1 . To reduce unwanted objects and separate connected bones in the binary image, a multiple template matching model was used to extract the bone area. After that, they used a graph-based method to extract the real bone structure and remove non-bone tissues. This method was based on thinning all the structures in the binary image to one pixel width. The center line of the structure was then found as a shortest distance between the two extreme points using Dijkstra algorithm. Support Vector Machine (SVM) with five geometrical features that describes the bone was then employed to build a bone model to eliminate any center line that does not fit the model. To refine the result, a trained decision tree classifier was tested by the geometrical features of existing bones and their count. The output of the classifier is how many missing bones objects existed.

Despite the fact that there are numerous techniques for dental specialist picture operation prediction, it is as yet important to create precise class discovery strategy to support dental specialist. The primary inconvenience of these strategies is that the assessment of the framework was finished utilizing skeletal or X-ray teeth pictures, which are totally unique in relation to common ones. The issue of the old style approach of dental class picture predict is that it is extremely hard to fabricate a decent attributes extractor and that it should be straightened out for every added appliance.

Our commitment is as per the following: we propose an arrangement of location, grouping, and prediction of dental pictures operations utilizing simple image processing and statistical techniques. This framework can be helpful for dental specialists to order dental pictures into Class I, Class II, and Class III and predict the yield aftereffects of Class II and Class III medicines. Basically, the detection and prediction of dental images has been a visual routine, originally based on visual-material evaluation and radiographic assessment.

\section{Problem Description}

Facial style in dentistry has had increased extraordinary consideration as of late. The accomplishment of orthodontic treatment is every now and again identified with the improvement picked up in patient's 
facial appearance, which consolidates soft tissue profile and since there is a huge assortment in soft tissue covering, misleading closures can be made if assurance and treatment organizing relies upon dental and skeletal estimations alone; in this manner, examination of soft tissue profile is required [11]. Our study is centered around soft tissue investigation. In other words, there are three principle dental picture classes: Class I (see Figure 1), Class II (see Figure 2), and Class III (see Figure 3).
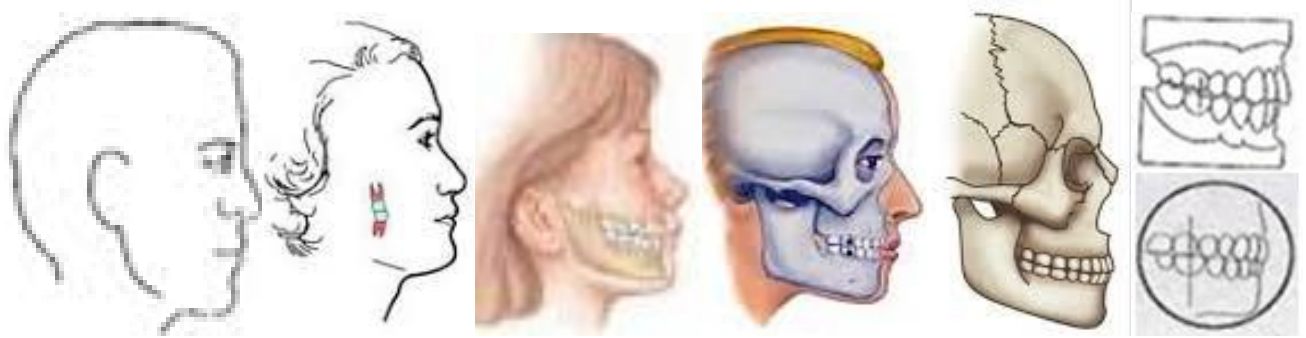

Figure 1: Class I
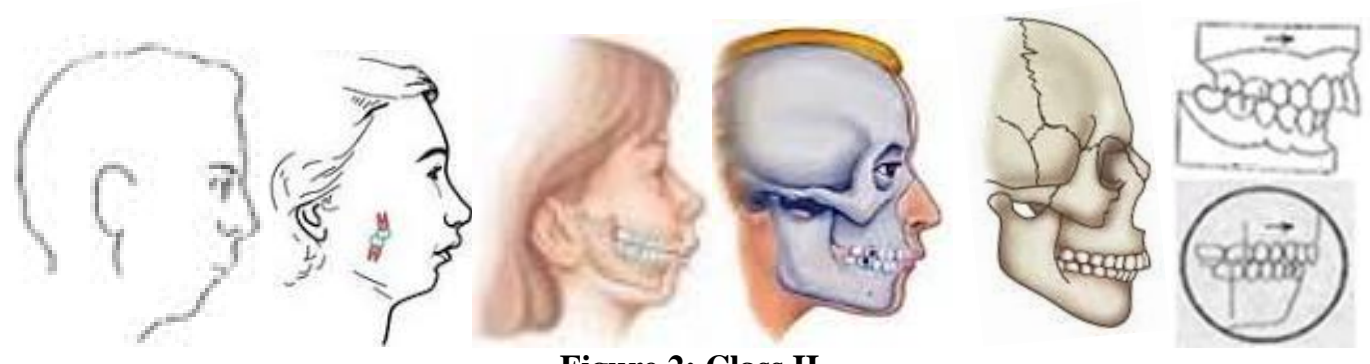

Figure 2: Class II
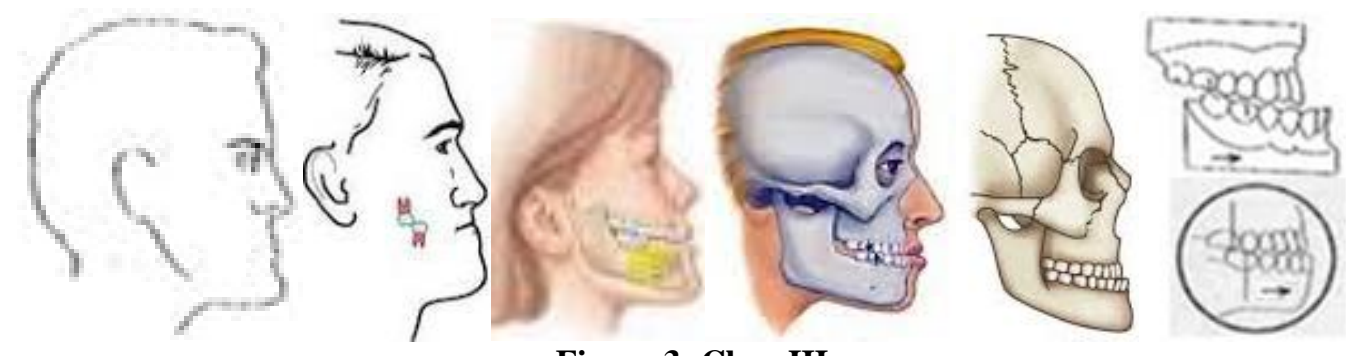

Figure 3: Class III

The dental medications are helpful to get great shapes. The ideal results of dentist operations are demanded for every treatment. Be that as it may, the perfect great shapes are exceptionally hard to get at any rate nowadays. Figure 4 shows the instances of Class II before and after ideal operations. Figure 5 shows the instances of Class III before and after ideal operations.
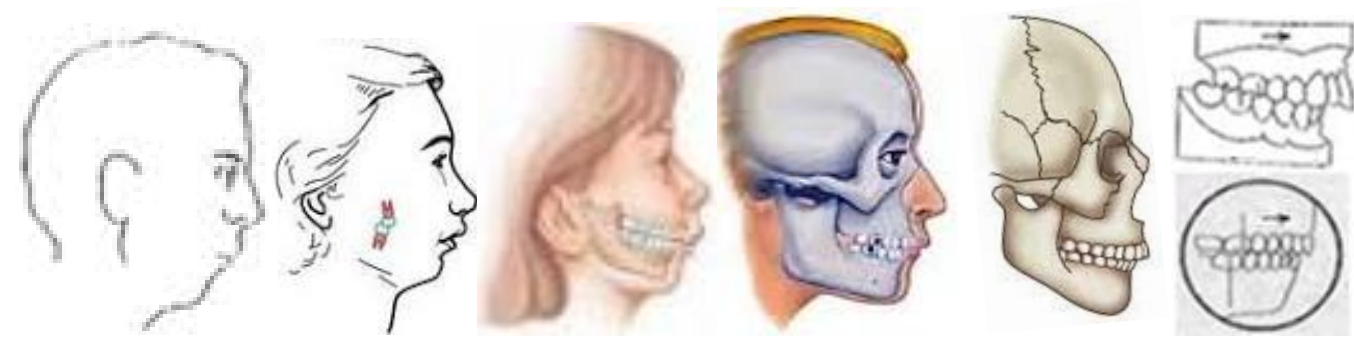

(a) Before operations 

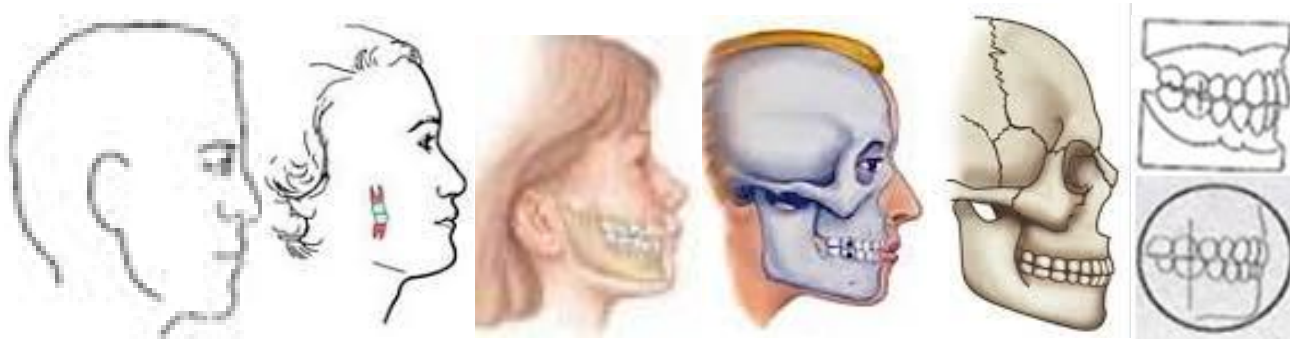

(b) After ideal operations

Figure 4: Class II correction
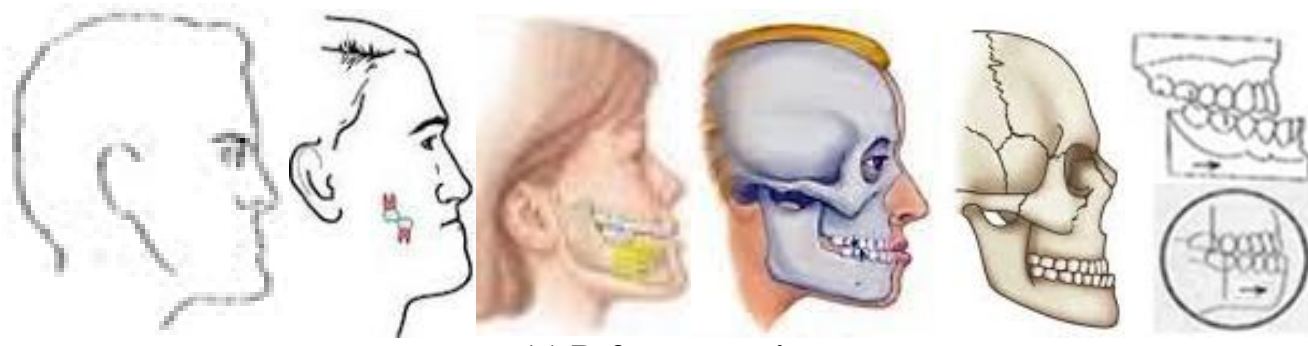

(a) Before operation
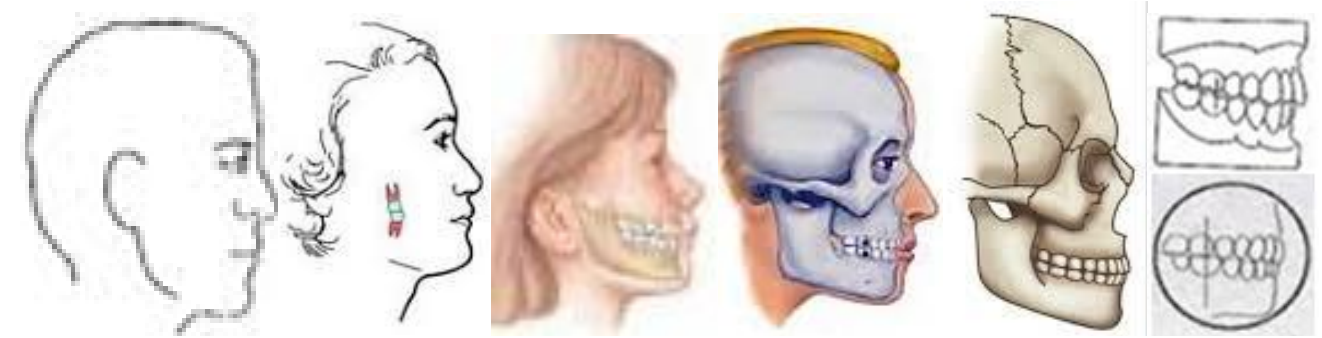

(b) After ideal operation

Figure 5: Class III correction

However, in this paper, we are presenting an approach to predict approximate results of dentist treatments.

The following criteria were excluded from the research:

1. Early or present orthodontic operation.

2. Missing teeth.

3. Obvious periodontal sickness.

4. Evidence of past injury/clinical system.

5. Facial dissymmetry or deformation.

6. Current of temporary/ maintained teeth.

7. Current of any hypochrondriast/ pathological circumstances.

8. Proximity of transitory or over maintained teeth.

\section{AEPRD Algorithm}

As of late, numerous researchers have proposed methods utilizing image processing scheme to solve predicted dentist operation problems. This study is involved in building a prediction model that combines the advantages of statistical algorithms and image processing techniques named AEPRD. Before authoritatively explaining the AEPRD method level structure, we want to acquaint some fundamental information with better understandability (see Figure 6).

A. Pre-processing for each image:

1. Read the image.

2. Resize the image to $200 * 100$ pixels.

3. Rotate the image to the left side. 
4. Divide the image and take the useful part (lips and chin).

5. Resize the image to $100 * 50$ pixels.

6. Remove the noise and enhance the image.

7. Make it black and white.

8. Take the outer edge.

B. Identify image groups:

1. Divide the images into three classes (Class I, Class II and Class III).

C. Segment and take the useful part of the two classes (Class II and Class III):

1. Take the images of each set and find minimum, maximum, mean, standard deviation, and lip thickness (upper lip of Class II and lower lip of Class III) of each class.

D. Do image processing:

1. Take an image from each set (Class II, Class III) and enter it to the program and push the selected lip area to the back with a threshold.

2. Display the predicted images.

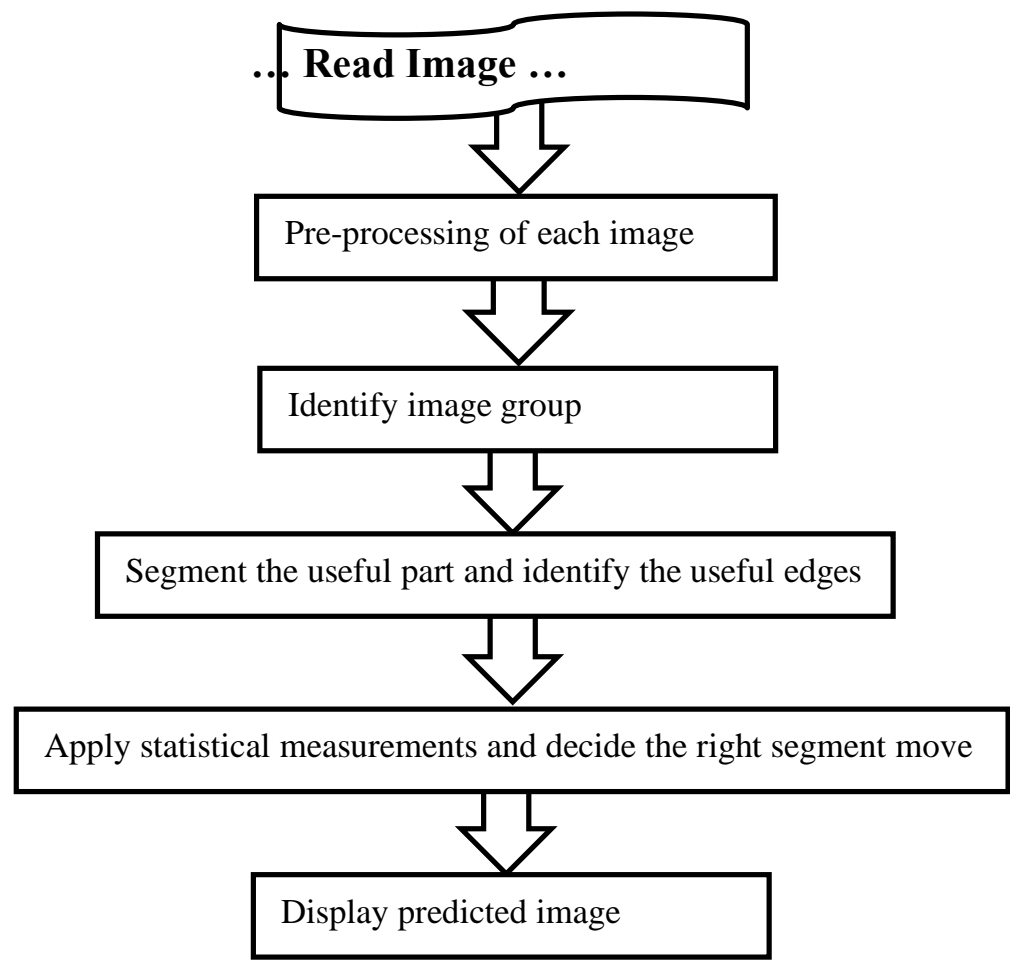

\section{IMAGE PRE-PROCESSING}

Figure 6: The algorithm steps

The proposed algorithm for predicting dentist image operation receives an image from the resource then puts it in a buffer and removes the noise to prepare for the next stage, i.e. parallel pictures that signify frontal area and foundation pixels with non-zero and zero qualities, separately.

\section{IDENTIFICATION OF PATIENT CLASS}

Human shapes are commonly partitioned into three kinds. Naming, the ordinary chomp (which called Class I), the over fly nibble/prognathism (which called Class II), and the negative over fly chomp/retrognathism (see Figures 1-3 separately). In this progression we are concentrating on the pictures of the two classes (Class II and Class III). To accomplish this, we are dependent on image labels. The proposed strategy utilizes the classes for predicting step.

\section{TRAINING}

The next stage of predicting dentist image operation is training step, i.e., training on Class II and Class III. This will help establish discovering the most important features of each class. The progression 
incorporate makes four gatherings of areas made out of stable pixels and sets up their relationship with the identified class.

In other words, a group of Class II before operations, Class II after operations, Class III before operations, and Class III after operations.

\section{TESTING}

The next step of proposed algorithm is testing sage, i.e., testing on Class II and Class III. This step includes testing some images belonging to the patients of Class II and Class III that have been treated. In other words, people who have undergone some surgical operations.

The following phase of investigation predicting dentist image treatment is made out of identified pixels and sets up their association with the recognized classes.

\section{PREDICTION}

So as to demonstrate that this method gives information that might be utilized for effective predicting of unknown patient class treatment in reasonable circumstances, the method was enhanced with modules for classes arrangement and decision making. The classification and prediction modules are vital so as to separate classes identifying to question from other classes and predict future classes modifications. Different methodologies might be used for this assignment, running from straightforward prediction dependent on neural network [4], to complex models prepared with image features [7].

After introducing the main preliminary steps of the algorithm, we are going to present the suggested method. Figure 7 summarizes the code explanation of the essential AEPRD method. The inputs are images and the outputs are predicted images of Class II and Class III.

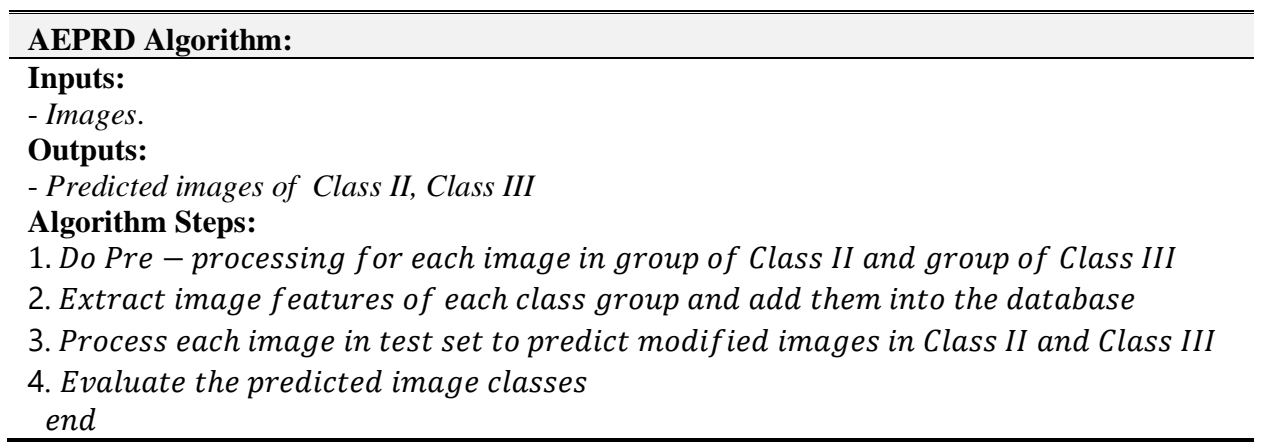

\section{Figure 7: Steps of the method}

\section{Evaluation of the Suggested Algorithm}

Here, we shall asses the effectiveness of the proposed method from the accuracy and efficiency concepts of the approach. Firstly, we will introduce some correctness criteria (Sec. 5.A). Then, we will present the selected datasets that will use for testing (Sec. 5.B). After that, explain the empirical evaluation protocol (Sec. 5.C). Then, we will introduce the experimental results (Sec. 5.D) and finally discussion the outcome of the method (Sec. 5.E).

\section{EVALUATION CRITERIA}

Correctness of the prediction methods can be evaluated via varies approaches which found in the literature [12]. This research chose the supervised methods to assess the accuracy of the proposed method. We build datasets which contain known classes as the ground truth for testing the "closeness" of the predicted classes results produced by the algorithm to the ground truth. The closer the resulting persistent classes to the known classes, the more accurate is. Those criteria including purity and entropy.

Purity was utilized in [13] and entropy in [14]. Purity alludes to the extent of the pictures having a place with a known class that are classify by a method. The higher the estimation of this parameter (between $[0,1]$ ) is, the better the method is [15]. Entropy reflects the amount of the photos of different classes in the first dataset that are designated to a class by the strategy. The estimation of this measure is between $\left[0, \log _{2} \mathrm{~N}\right]$ where $\mathrm{N}$ is the quantity of various classes included. For the most part, the littler 
estimation of the entropy is, the better the prediction method is [16]. The proficiency of a method was estimated by the measure of time in seconds taken for the method in finishing the predicting task.

\section{DATASET USED}

All the experiments have done with selected datasets. In details, we created four datasets each one has 50 images. Each two datasets belong to a specific class. DS1 contains images of Class II before operations (Figure 8 contains some images of this class), DS2 contains images of Class II after operations (Figure 9 contains some images of this class), DS3 contains images of Class III before operations (Figure 10 contains some images of this class), and DS4 contains images of Class III after operations (Figure 11 contains some images of this class).

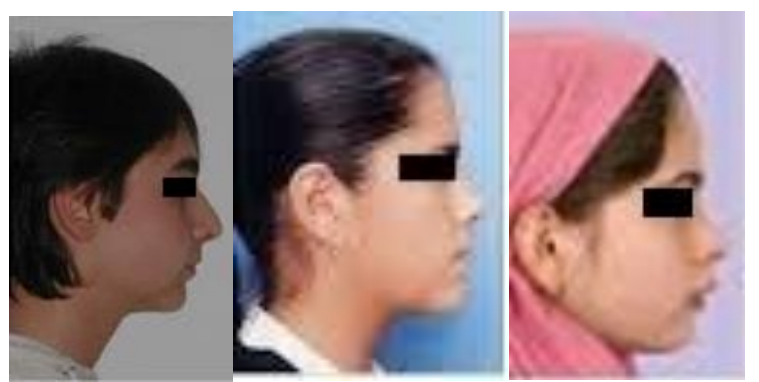

Figure 8: Images of Class II in DS1 before operations

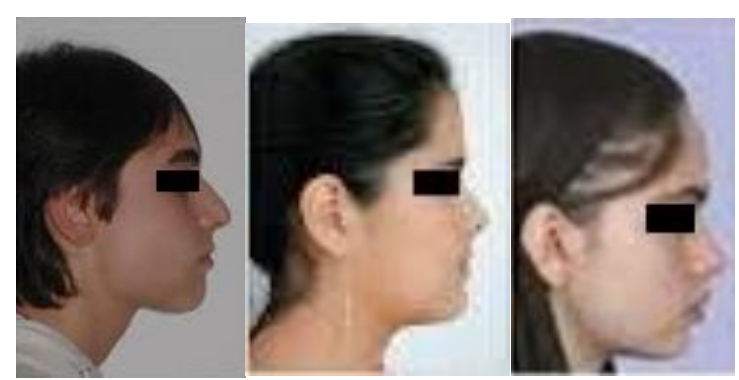

Figure 9: Images of Class II in DS2 after operations

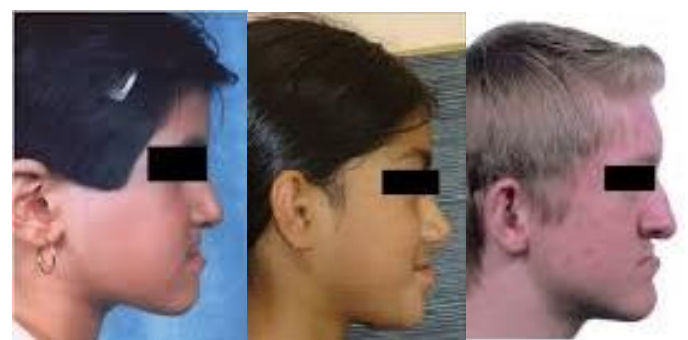

Figure 10: Images of Class III in DS3 before operations

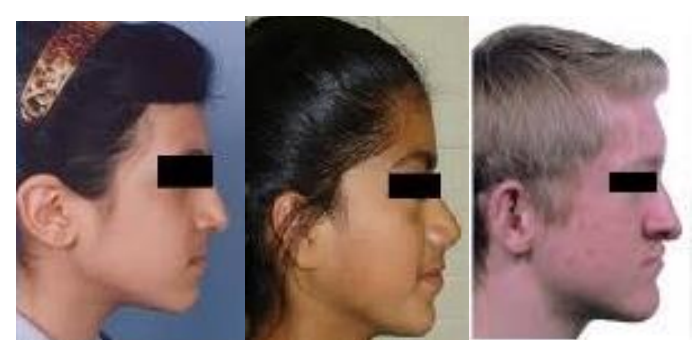

Figure 11: Images of Class III in DS4 after operations 
In addition, we used two more datasets to predict specific classes. In more details, DS5 contains images of Class II before operations (Figure 12 contains some images of this class) and DS6 contains images of Class III before operations (Figure 13 contains some images of this class).

We concurred that there are a few downsides of the chose datasets. They didn't have a wide range of different features. In future work, this method will evaluated on more complicated datasets.
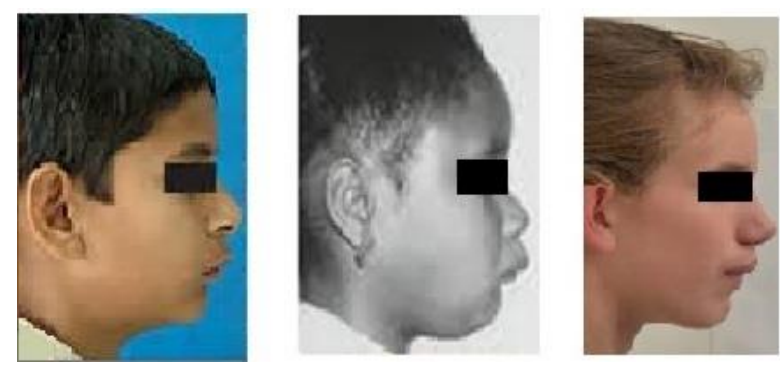

Figure 12: Images of Class II in DS5 before predicted operations
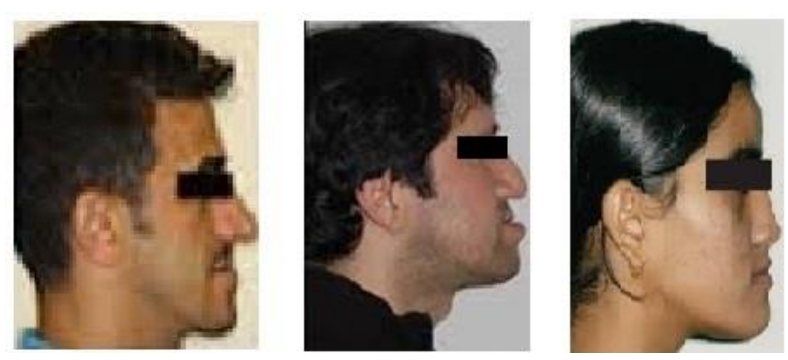

Figure 13: Images of Class III in DS6 before predicted operations

\section{EMPIRICAL EVALUATION PROTOCOL}

To test the performance of the proposed method and compare it with the two existing methods, we divided the datasets into two groups: the training set (DS1, DS2, DS3, and DS4) and predicting set (DS5 and DS6). This is because the existing algorithms treat the input images in this way. For fairness we have made the proposed algorithm to be tested using the same protocol. The experiments were replay 100 times, and the average was considered.

We applied AEPRD algorithm to the selected datasets (SD1, SD2, SD3, and SD4) for training. As mentioned in Section 4, we read the original image, segment it to take the useful part, change it to gray image, enhance the image, identify the borders, and change it to the black and white image. Figure 14 shows the steps that we applied for images of Class II before operations (DS1). Figure 15 displays the steps that we followed for images of Class II after operations (DS2). Figure 16 shows the steps that we applied for images of Class III before operations (DS3). Figure 17 shows the stages that we developed for images of Class III after operations (DS4). 

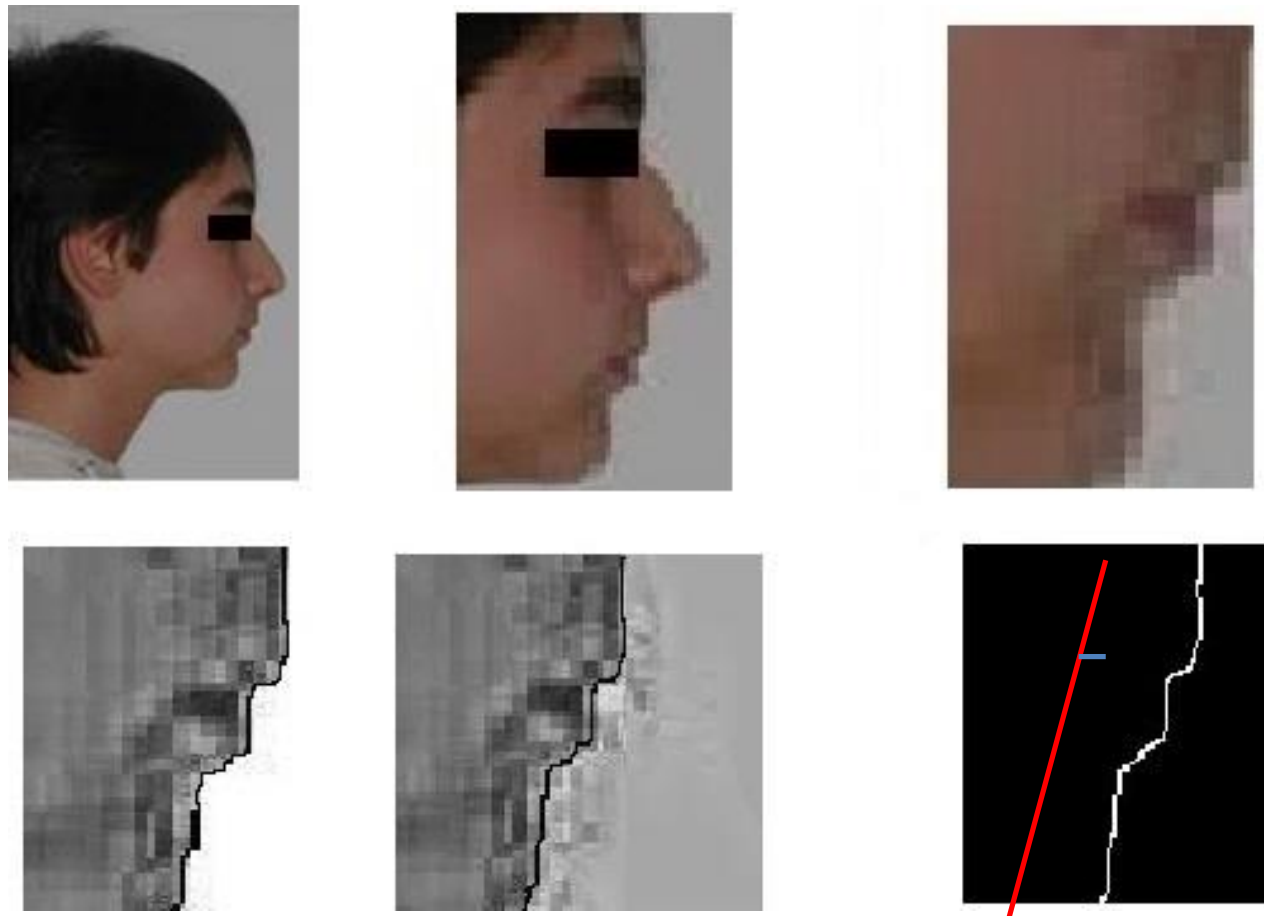

Figure 14: Algorithm steps in DS1
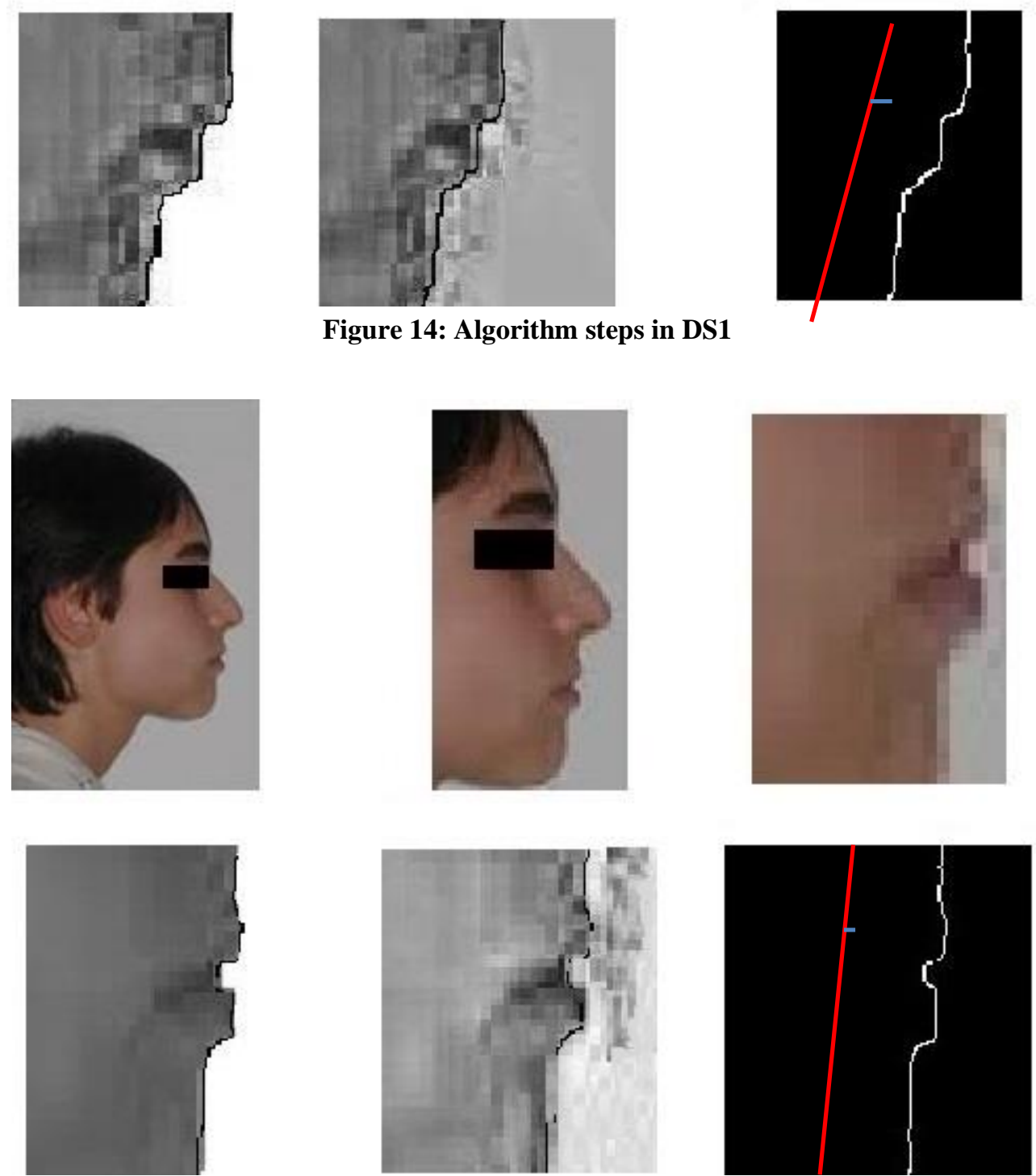

Figure 15: Algorithm steps in DS2 

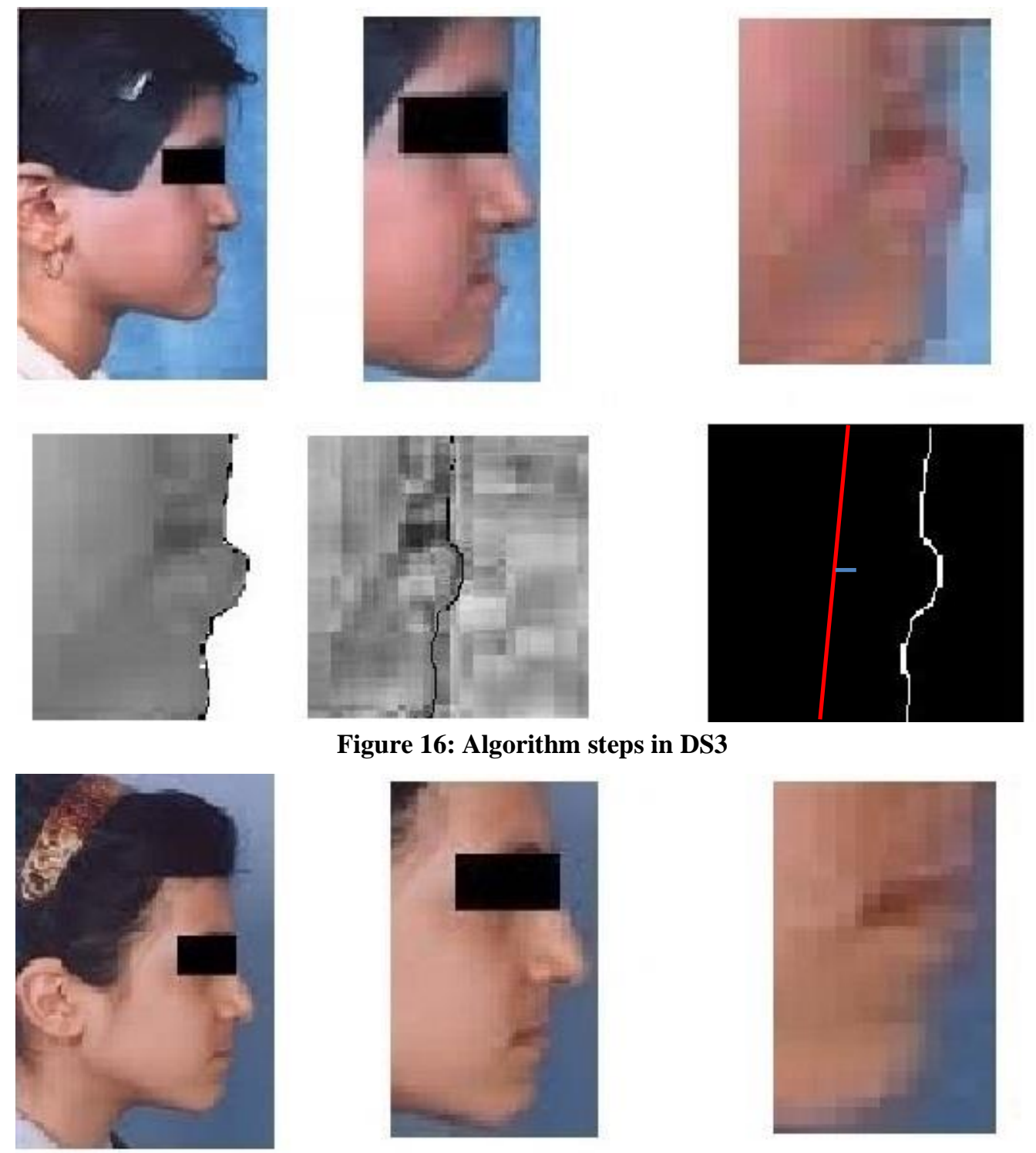

Figure 16: Algorithm steps in DS3
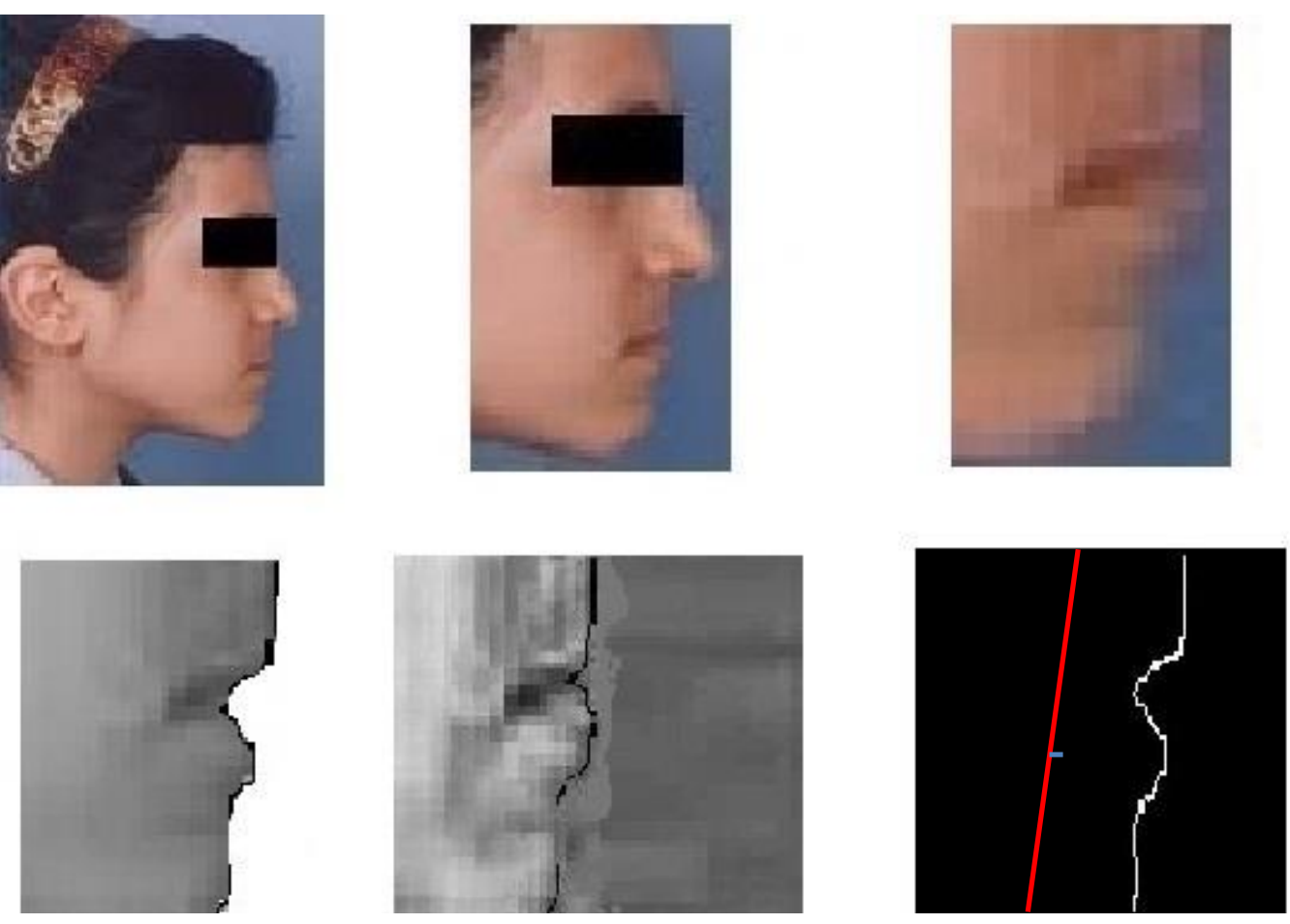

Figure 17: Algorithm steps in DS4

After we applied the AEPRD method to the chose datasets, we recognized the estimations of minimum, maximum, mean, standard deviation, and lip thickness of each class. The mean estimation of Class II before operation is 44.6030 with STD value 1.3705 and upper lip thickness $15 \mathrm{~mm}$. The mean estimation of Class II after tasks is 34.1578 with STD value 1.657 and upper lip thickness $5 \mathrm{~mm}$. The mean estimation of Class III before activities is 36.0525 with STD value 1.7975 and lower lip thickness $18 \mathrm{~mm}$. The mean estimation of Class III after tasks is 32.218 with STD value 1.720 and lower lip thickness $7 \mathrm{~mm}$. Table 1 sums up the yield values. 
Table 1: Summarization of training classes of AEPRD method

\begin{tabular}{|c|c|c|c|c|c|}
\hline & Minimum & Maximum & Mean & Standard Deviation & Lip Thickness \\
\hline Class II Before Operations & 40 & 46 & 44.6030 & 1.3705 & Upper $15 \mathrm{~mm}$ \\
\hline Class II After Operations & 32 & 38 & 34.1578 & 1.657 & Upper $5 \mathrm{~mm}$ \\
\hline Class III Before Operations & 33 & 38 & 36.0525 & 1.7975 & Lower $18 \mathrm{~mm}$ \\
\hline Class III After Operations & 31 & 34 & 32.218 & 1.720 & Lower $7 \mathrm{~mm}$ \\
\hline
\end{tabular}

MATLAB programming was utilized to examine the aftereffects of every method.

\section{ALGORITHM STEPS AND PREDICTED OUTPUT RESULTS}

The output values of previous step were used to predict each class after operations. In other word, we take an image from test datasets (DS5 and DS6), calculate the summation of ones of final output black/white image, shift the assigned area, and compare it with benchmark table. Figure 18 shows the steps that we applied for images of Class II before predicted operations (DS5). Figure 19 shows the steps that we applied for images of Class III before predicted operation (DS6).

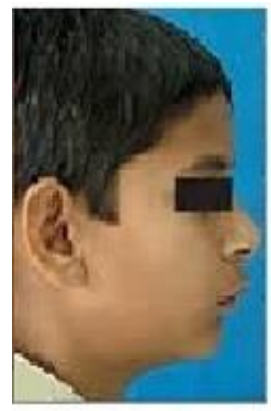

(a)

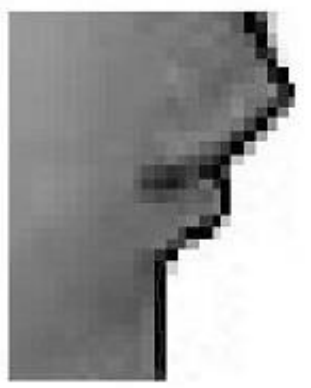

(d)

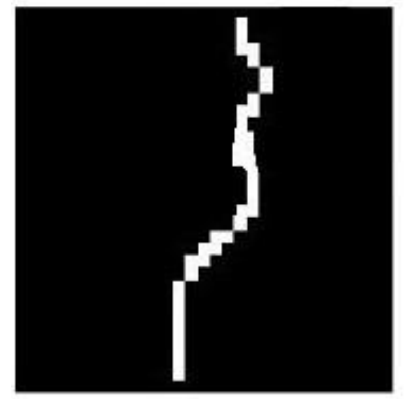

(g)

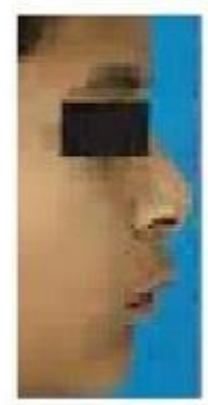

(b)

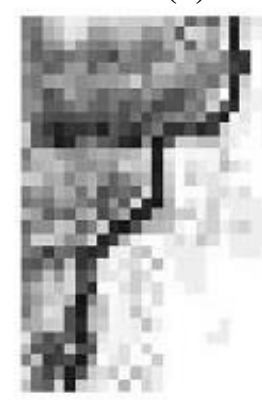

(e)

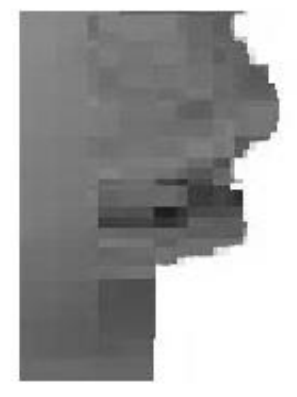

(h)

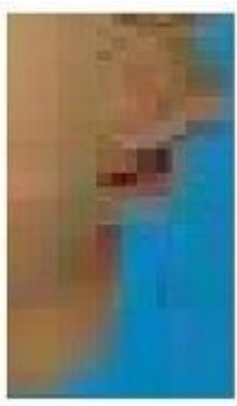

(c)

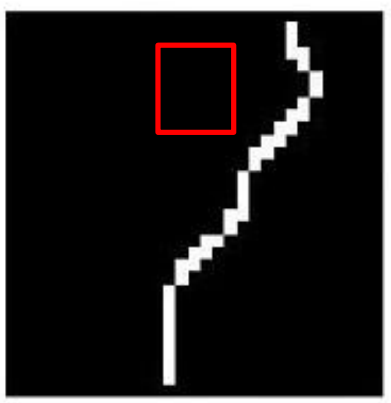

(f)

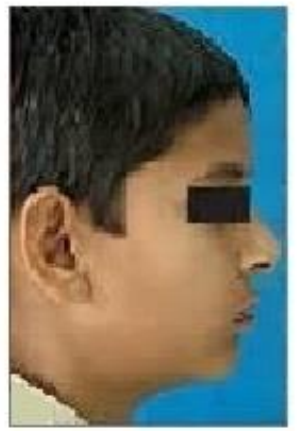

(i)

Figure 18: Algorithm steps in DS3 


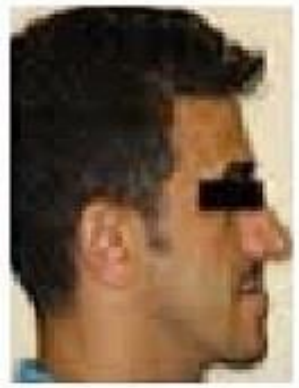

(a)

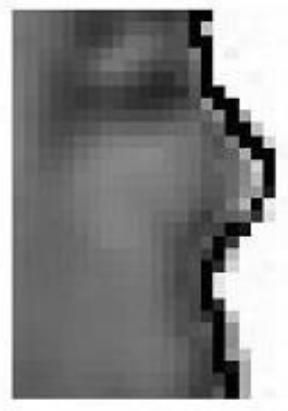

(d)

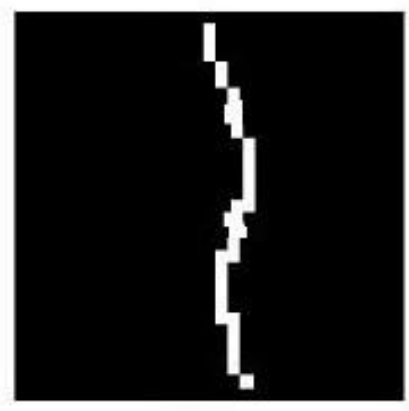

(g)

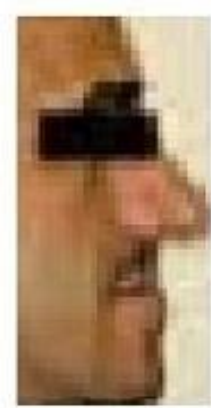

(b)

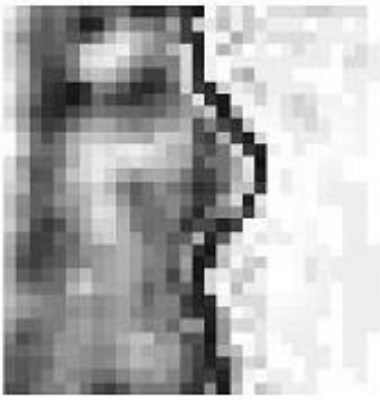

(e)

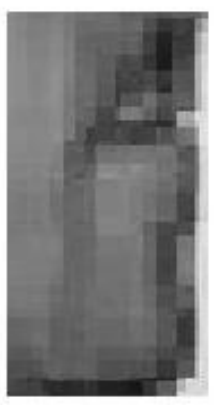

(h)

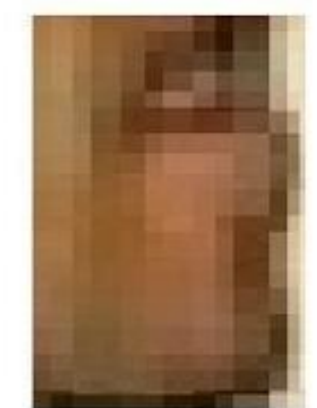

(c)

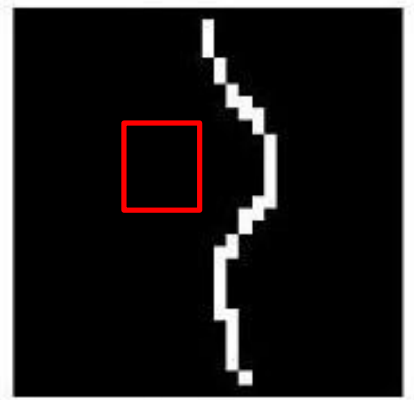

(f)

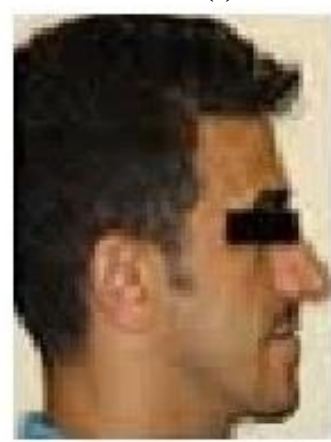

(i)

Figure 19: Algorithm steps in DS4

Figure 20 shows some images of Class II after predicted operations (DS7). Figure 21 shows some images of Class III after predicted operations (DS8).

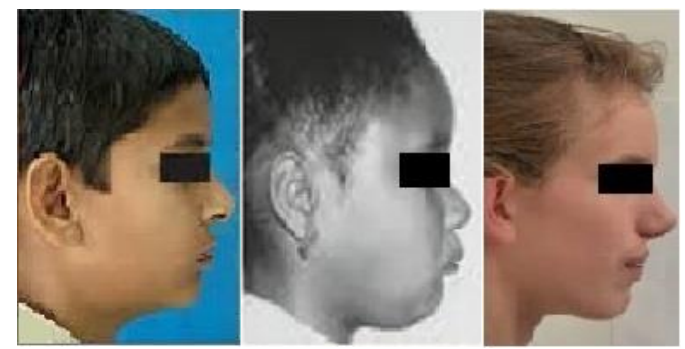

Figure 20: Images of Class II in DS7 after predicted operations

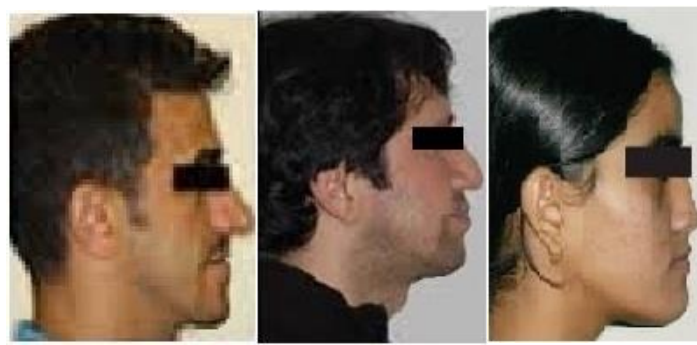

Figure 21: Images of Class III in DS8 after predicted operations 


\section{EXPERIMENTAL RESULTS}

\section{- Purity}

Figure 22 displays the details of comparability outputs between the original classes and the result classes from the DenNN, DenSTM, and AEPRD algorithms respectively. AEPRD has the highest purity. This is the result of the stringent prediction strategy deployed and the new technique of preprocessing images. DenSTM also has good purity by utilizing the Holdaway rules and Planmeca Romexis Cephalometric Analysis Software. DenNN has the poorer purity because of its strategy of utilizing of neural network in prediction images.

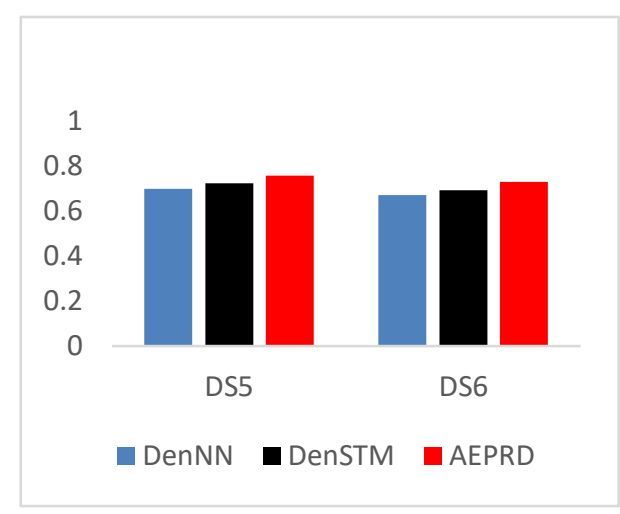

Figure 22: The purity measurement.

\section{- Entropy}

As shown by Figure 23, AEPRD has the lowest entropy because it depends on simple statistical measurements and very careful threshold. DenSTM has the second lowest level because of applying Planmeca Romexis Cephalometric Analysis Software lead to error predicting some images. DenNN has the third level because the random number of hidden layers in neural network lead to error predicting several images.

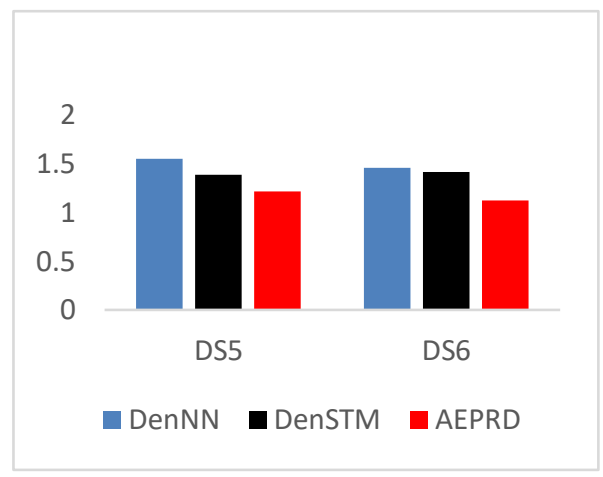

Figure 23: The entropy measurement

\section{Efficiency Evaluation}

\section{- Execution Time}

Execution time is the proportion of the measure of utilizing time in seconds that proceed for the method in finishing the prediction method. Concerning implementation time, the AEPRD method has the less execution time pursued by DenNN and DenSTM respectively (see Figure 24). 


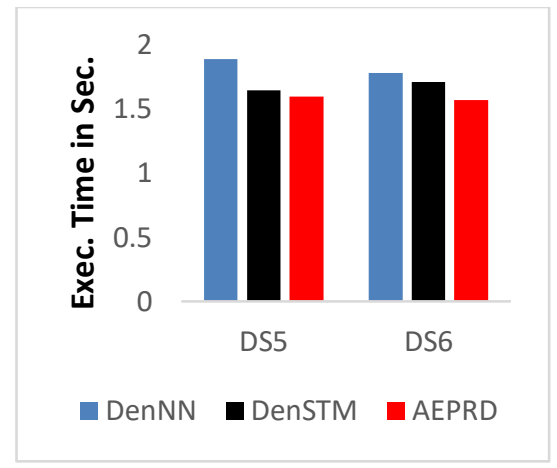

Figure 24: The efficiency measurement

After getting these output results we could approve that AEPRD method is faster than DenSTM and DenNN.

\section{DISCUSSION}

An individual's capacity to perceive an excellent face is intrinsic, yet making an interpretation of this into characterized treatment objectives is risky. Perceiving magnificence is not polished nor is it troublesome. The impression of magnificence is an individual inclination with social predisposition. Rules administering why a face is excellent are not comprehended nor required for anybody to state that a face is wonderful. Specialists and wellbeing experts have endeavored to characterize and reproduce a perfect face. They perceive excellence, yet target gauges are troublesome, in spite of ceaseless endeavors to explain this idea. As wellbeing experts have expanded their capacity to change faces, the need to comprehend what is and is not lovely has escalated. Truly, orthodontics have included facial congruity as one of their significant objectives alongside occlusal greatness. Edward Hartley [17] proposed that if teeth were set in ideal impediment, great facial concordance would result. The facial skeleton and its overlying soft tissue decide facial congruity and equalization. It is the structure of the overlying soft tissues and their relative extents that give the visual effect of the face [17].

Conservation of facial engaging quality is an essential objective of orthodontic treatment. Treatment arranging requires information on the boundaries and regularizing information that assists with building up objectives and anticipate the hindrances that should be arranged. As soft tissue standards fill in as a rule in ascertaining change it has been recommended that certain cephalometric gauges relating teeth to cranial or facial bones could guarantee great facial structure whenever clung to as a treatment objective. The accomplishment of facial soft tissue proportionality is one of the foremost objectives in the treatment of dentofacial deformations and can be accomplished with appropriately arranged and executed orthognathic medical procedure methods. Therefore the aim of this study is to calculate the norms so that the soft tissue cephalometric values of various parameters could be differentiated so as to guide the orthodontist towards a better diagnosis and treatment planning of dentofacial deformities.

The joined aftereffects of all trials demonstrate that the proposed calculation gives information on preparing dataset which, subsequent to utilizing the characterization, prompts fruitful forecast pictures. Contrasted with other late methodologies with anticipate picture classes activities, e.g., [4] [6] [7] the calculation introduced in this paper is moderately straightforward, both theoretically and computationally. It doesn't require complex methodologies, for example, web based learning, probabilistic models, conduct demonstrating, and so forth. The calculation utilizes fundamental scientific and measurable tasks for demonstrating the pictures classes and the necessary number of calculations relies upon picture content. Along these lines, this calculation is anything but difficult to execute in a working framework, for instance in an installed framework inside the versatile applications. As far as computational unpredictability, the most tedious stage are preparing and prehandling. 
The major promise of the AEPRD method is the easiness and high flexible structure. This consist of the main functions of the method: pre-prcessing image, identify classes, identify training and testing images, predicting operation results of unknown images, and save images in a database. All process were allocated as functions which means we could simultaniosly enhance every function apart without modifying the overall main structure of the method.

There were propostions of more enhancements of every operation inside the method. Firstly, we know that utilising separate functions cause slow process to predict classes operations. Therefore, we could replace those processes by one function, such as using computational topology to identify and predict the classes operations. Machine learning techniques and fuzzy-based approches could be consider to produce more effecint functions to produce more accurate predictions of classes operations.

\section{Conclusion And Future Work}

Soft tissue profile is currently one of the most critical areas of interest in the selection of orthodontic treatment. The facial soft tissues are viewed as a powerful structure that can create alongside or free of their skeletal foundation. The planning of early treatment is vital for an effective result. A few investigations have announced that treatment ought to be done in patients under 10 years old to improve the orthopedic impact. This study concluded that the hybrid statistical and image processing method is as reliable as the anatomic point method and both of them could be used in cephalometric soft tissue analysis. Anticipating teeth picture classes tasks is a significant advance during the time spent unattended teeth picture recognition. Such picture must be anticipated in the picture streams with high exactness so as to give fundamental information to the choice module. The proposed method takes care of the issue of anticipating teeth picture activities via preparing the module and testing the new picture. This method was planned such that makes it simple to actualize it in the system for online occasion discovery and versatile applications. The algorithm was evaluated with existing methods and achieved high purity with 0.755 and low purity with 1.212. Future work will focus on updating the method. Because of the method is flexible, those updating thoughts can deals with the major functions of the method. Firstly, we will investigate the topology computation to present more sophisticated version of the preprocessing step. Secondly, we will investigate hybridizing different prediction algorithm, like neural network-based, swarm-based, and genetic-based methods to test the modularity of AEPRD method.

\section{References}

[1] Medicalnewstoday, "www.medicalnewstoday.com/articles/249482.php," medicalnewstoday, 2018. [Online]. Available: https://www.medicalnewstoday.com/articles/249482.php. [Accessed: 01-Feb-2020].

[2] A. M. Shafi, F. Naseem, A. Khan, and A. G. Khan, "A Soft Tissue Cephalometric Analysis for Pakistani Adult Using Holdaway's Analysis,” vol. 25, no. 1, pp. 51-53, 2018.

[3] A. P. Publication, “A Review of Dental Caries Detection Technologies,” 2015.

[4] R. Ben Ali, R. Ejbali, and M. Zaied, "Detection and Classification of Dental Caries in X-ray Images Using Deep Neural Networks,” no. c, pp. 223-227, 2016.

[5] R. J. Peterman, S. Jiang, R. Johe, and P. M. Mukherjee, "Accuracy of Dolphin visual treatment objective ( VTO ) prediction software on class III patients treated with maxillary advancement and mandibular setback," Prog. Orthod., 2016.

[6] A. F. Kamaruddin, "SOFT TISSUE CEPHALOMETRIC ANALYSIS OF MALAY ORTHODONTIC PATIENTS," vol. 9, no. 4, pp. 157-165, 2018.

[7] S. A. Mohammed, J. E. Saloom, and H. M. Hussien, "Quantifying the Soft Tissue Profile by Two Different Methods in Iraqi Adults : A Comparative Study,” pp. 15-21, 2019. 
[8] G. Jader, J. Fontinele, M. Ruiz, K. Abdalla, M. Pithon, and L. Oliveira, "Deep instance segmentation of teeth in panoramic X-ray images."

[9] J. S. Lee, J. W. Wang, H. H. Wu, and M. Z. Yuan, "A nonparametric-based rib suppression method for chest radiographs,” Comput. Math. with Appl., vol. 64, no. 5, pp. 1390-1399, 2012.

[10] X. Li, S. Luo, and Q. Hu, “An Automatic Rib Segmentation Method on X-Ray Radiographs,” Int. Conf. Multimed. Model. Springer Int. Publ., pp. 128-139, 2015.

[11] P. J. Khot, M. Agrawal, J. Agrawal, L. Nanjannawar, V. Kagi, and M. Khot, "Evaluation of Soft Tissue Cephalometric Norms for Maharashtrian Population Using Holdaway Analysis," vol. 5, no. 11, pp. 29-33, 2018.

[12] A. Al Abd Alazeez, S. Jassim, and H. Du, "EINCKM: An Enhanced Prototype-based Method for Clustering Evolving Data Streams in Big Data," Proc. 6th Int. Conf. Pattern Recognit. Appl. Methods, no. Icpram, pp. 173-183, 2017.

[13] A. Al Abd Alazeez, S. Jassim, and H. Du, "EDDS: An Enhanced Density-Based Method for Clustering Data Streams,” 2017 46th Int. Conf. Parallel Process. Work., pp. 103-112, 2017.

[14] A. Al and A. Alazeez, "TPICDS : A Two-phase Parallel Approach for Incremental Clustering of Data Streams," Int. Conf. High Perform. Comput. HPC Bristol, p. 12, 2018.

[15] A. T. Y. Al Abd Alazeez, S. Jassim, and H. Du, "SLDPC : Towards Second Order Learning for Detecting Persistent Clusters in Data Streams," 2018 10th Comput. Sci. Electron. Eng., vol. 9781-5386, pp. 248-253, 2018.

[16] H. L. Nguyen, Y. K. Woon, and W. K. Ng, "A survey on data stream clustering and classification," Knowl. Inf. Syst. Springer, pp. 535-569, 2015.

[17] S. Upadhyay, A. Sharma, and D. Phor, “Assessment of Arnett' s Soft Tissue Norms For Himachali Population Using Digital Tracing Method : A Cephalometric Study Abstract :," vol. 17, no. 10, pp. 83-90, 2018. 